\title{
Characterization by Thermogravimetric Analysis of Polymeric Concrete with High Density Polyethylene Mechanically Recycled
}

\author{
Alma Delia Rodríguez Martínez¹, Martha Lilia Domínguez Patiño², \\ Rosa María Melgoza Alemán², Gerardo Antonio Rosas Trejo3 \\ ${ }^{1}$ Graduate Engineering and Applied Science, Autonomus University of the State of Morelos, Chamilpa, Morelos, \\ México \\ ${ }^{2}$ Faculty of Chemical Sciences and Engineering, Autonomus University of the State of Morelos, Chamilpa, \\ Morelos, México \\ ${ }^{3}$ Metallurgical Research Institute, University Michoacana de San Nicolás de Hidalgo, Morelia, Michoacán, \\ México \\ Email: arodriguez@uaem.mx
}

Received 19 February 2014; revised 25 March 2014; accepted 10 April 2014

Copyright (C) 2014 by authors and Scientific Research Publishing Inc.

This work is licensed under the Creative Commons Attribution International License (CC BY).

http://creativecommons.org/licenses/by/4.0/

c) (i) Open Access

\begin{abstract}
This paper presents the results of the characterization by thermogravimetric analysis of a new composite material called polymeric concrete. The polymeric concrete contains micro-particles obtained from High Density Poly-Ethylene (HDPE) mechanically recycled (post-consumer bottles); the official Mexican standard NMX-E-232-SCFI-1999 considers the HDPE as the recyclable plastic material. Thermo-grams based on weight lost were obtained from the raw material (HDPE) and the polymer concrete in order to obtain the glass transition temperature $\left(T_{g}\right)$ and melting temperature $\left(\mathrm{T}_{\mathrm{f}}\right)$. The analysis conditions were defined from $20^{\circ} \mathrm{C}$ to $180^{\circ} \mathrm{C}$ and the heat rate of $1^{\circ} \mathrm{C} /$ minute. The results show that the glass transition temperature of polymeric concrete is $46^{\circ} \mathrm{C}$ and the HDPE is $38^{\circ} \mathrm{C}$. These results mean that the polymeric concrete is more resistant to decomposition. With respect to the melting temperature, the results show that the $2^{\circ} \mathrm{C}$ difference between polymeric concrete and HDPE is not significant. The polymeric concrete with HDPE recycled can be considered as composite material thermoplastic. The new material melts when it is heated to $146^{\circ} \mathrm{C}$ and has the ability to be softened, processed and reprocessed with temperature and pressure changes, which make it possible to obtain molded pieces in the desired shape.
\end{abstract}

\section{Keywords}

Polymer Concrete, High Density Poly-Ethylene, Thermogravimetric Analysis

How to cite this paper: Rodríguez Martínez, A.D., Domínguez Patiño, M.L., Melgoza Alemán, R.M. and Rosas Trejo, G.A. (2014) Characterization by Thermogravimetric Analysis of Polymeric Concrete with High Density Polyethylene Mechanically Recycled. Journal of Minerals and Materials Characterization and Engineering, 2, 259-263.

http://dx.doi.org/10.4236/immce.2014.24030 


\section{Introduction}

The production and processing of new materials are an important part of our economy. The engineers must design products and the processes needed for its manufacture. The raw materials (materials) are transformed to products into processes. It is important to know the structure and properties of materials in order to select the most suitable materials for each application and develop the best methods for processing. The research and development engineers working to create new materials or to modify existing properties, the design engineers and others use some materials to design and create new products and systems [1].

Composite materials are classified based on matrix used. There are composite materials using metals, polymers or ceramics as matrix. In the present research was obtained a new composite material which uses polyester resin as polymeric matrix. Another classification of composite materials is according to the form of reinforcement or filler. Some composite materials could be classified as particulates, short fibers, continuous fibers or layered sheet [2]. High density polyethylene particulates were added as filler material in the developed polymeric concrete.

The polymer mixtures are mechanical combinations of polymers; such combinations do not depend on chemical bonds, but typically require compatibilizers that prevent the segregation of components. Typically maintained in the mixtures are some of the individual properties (impact resistance, weather resistance, better performance at low temperatures and flame delay) and in many cases the objective is to find two or more components which improve one or more of them. Recent researches are focused on the combination of polymers to obtain polymer mixtures and plastic alloys by use of coupling agents or compatibilizers as silanes, titanates and thermoplastic rubbers [3].

The polymer concrete (PC) developed is a new composite material (CM) considered as an alternative material in the construction industry. The reinforcement particles have approximately the same dimensions in all directions. The particles can be rods, spheres, flake and many other shapes whose size are about 10 microns. Size, shape and distribution can affect the properties of the CM.

Thermogravimetric analysis (TGA) was based on the measurement of the temperature changes that occur in a substance, either by chemical reactions or physical changes. TGA is a technique by which a sample is weighed and continuously heated at a controlled rate. The weights of samples change when the temperature increases. The resulting curve is called thermogram. The thermogram provides information about the thermal stability and composition of the original sample, the composition and stability of intermediates and the waste composition. Each material has its corresponding thermogram allowing identification [4].

\section{Methodology}

Raw material: polyethylene microparticles mechanically recycled high density, polyester resin, calcium carbonate.

Sample preparation RM CP with PET: a homogeneous mixture is made containing polyester resin and calcium carbonate microparticles recycled HDPE mechanically conventional mill in proportion (1:1:1) is poured into molds of polyethylene high density and allowed to dry at room temperature $\left(28^{\circ} \mathrm{C}\right)$ for about 6 hours. Figure 1 presents a flow chart for sampling with HDPE RM CP and testing or analysis for the characterization of the composite.

Thermogravimetric analysis (TGA): in an alumina crucible placed $0.01 \mathrm{~g}$ of powder with HDPE CP RM, which is placed in the sample holder for thermogravimetric analysis team flag previously calibrated SDT Q600 model, which is shown in Figure 2. The computer software program using temperature records begin in the range of $20^{\circ} \mathrm{C}$ to $180^{\circ} \mathrm{C}$ at a rate of heating $1^{\circ} \mathrm{C} /$ minute.

\section{Results}

Differential thermal analysis (DTA).

Figure 3 shows the thermogravimetric analysis of the raw material (filler in polymer concrete) particulates of recycled high density polyethylene mechanically.

Figure 4 shows the thermogravimetric analysis of composite materials (polymer concrete with recycled high density polyethylene mechanically). 


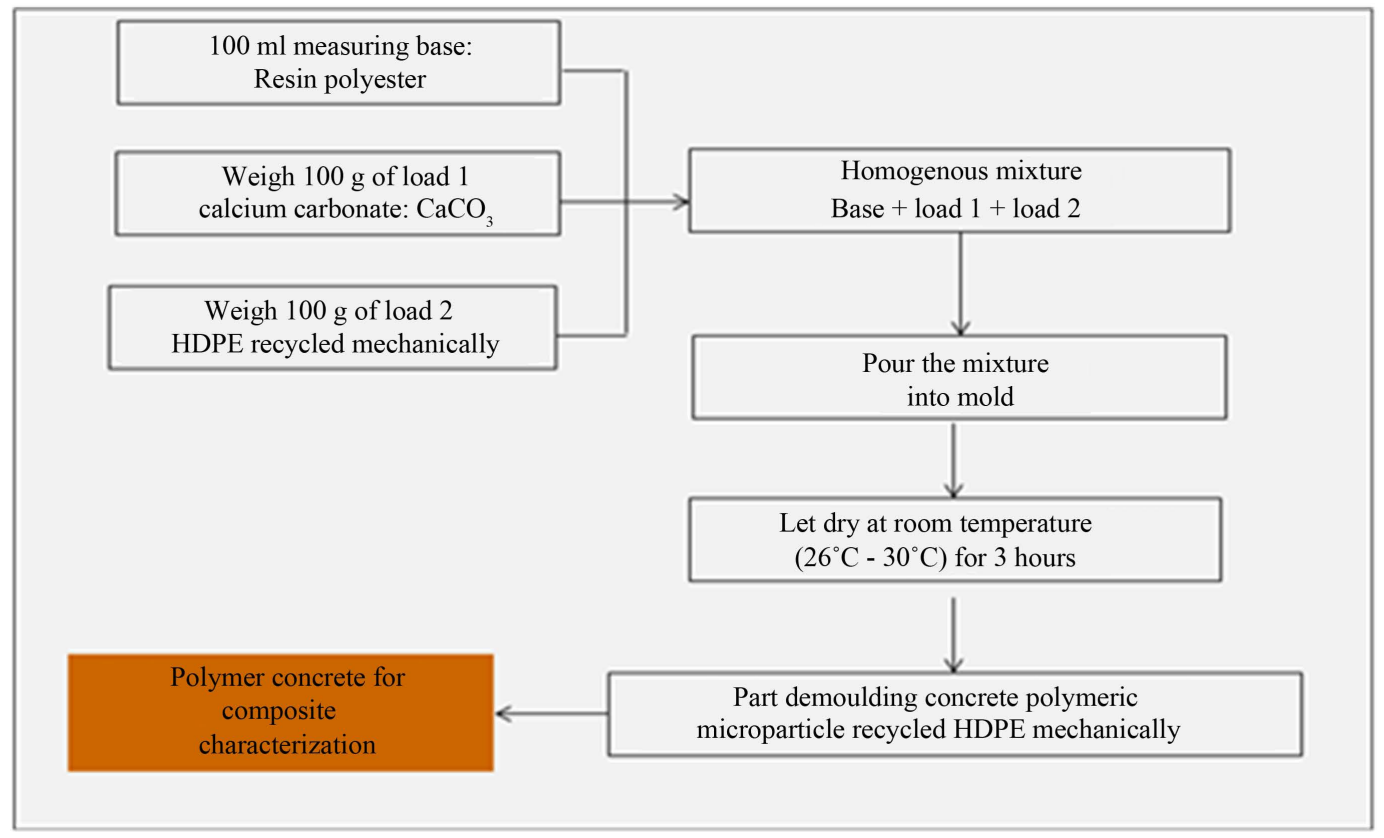

Figure 1. Flow chart for concrete samples polymeric microparticles recycled HDPE mechanically.

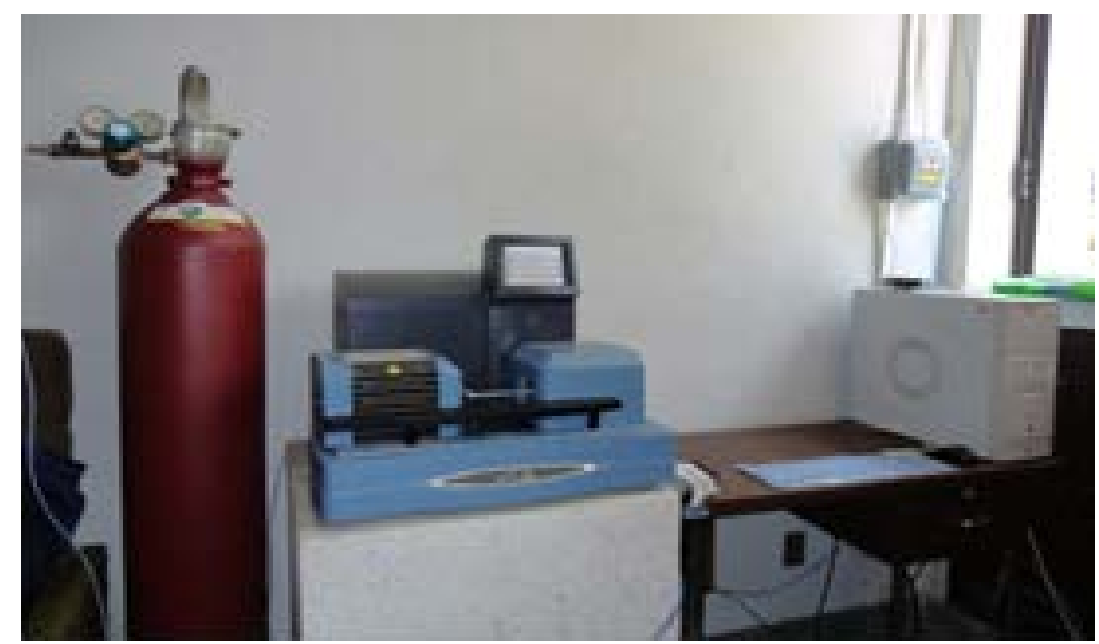

Figure 2. Thermogravimetric analysis equipment SDT600.

\section{Thermogravimetric Analysis (TGA)}

Microparticles HDPE mechanically recycled have a glass transition temperature $\left(\mathrm{T}_{\mathrm{g}}\right)$ at $38^{\circ} \mathrm{C}$. The polymer concrete has a $\mathrm{T}_{\mathrm{g}}$ of $46^{\circ} \mathrm{C}$.

Microparticles of high density polyethylene obtained by mechanical recycling have an initial weight loss at $59^{\circ} \mathrm{C}\left(\mathrm{T}_{\mathrm{WP}}\right)$ and the end weight loss at $126^{\circ} \mathrm{C}\left(\mathrm{T}_{\mathrm{WT}}\right)$. The final weight loss of HDPE sample was $4^{\circ} \mathrm{C}$ before melting temperature.

The PC has partial weight loss at $86^{\circ} \mathrm{C}\left(\mathrm{T}_{\mathrm{WP}}\right)$. The $\mathrm{T}_{\mathrm{WP}}$ of PC probably increases due to content of calcium carbonate as inert material.

The HDPE particulates have a melting temperature $\left(T_{f}\right)$ of $130^{\circ} \mathrm{C}$ and HDPE-PC have a $T_{f}=128^{\circ} \mathrm{C}$.

\section{Conclusions}

The polymer concrete with high density polyethylene (HDPE-PC) is classified as a polymeric composite and 


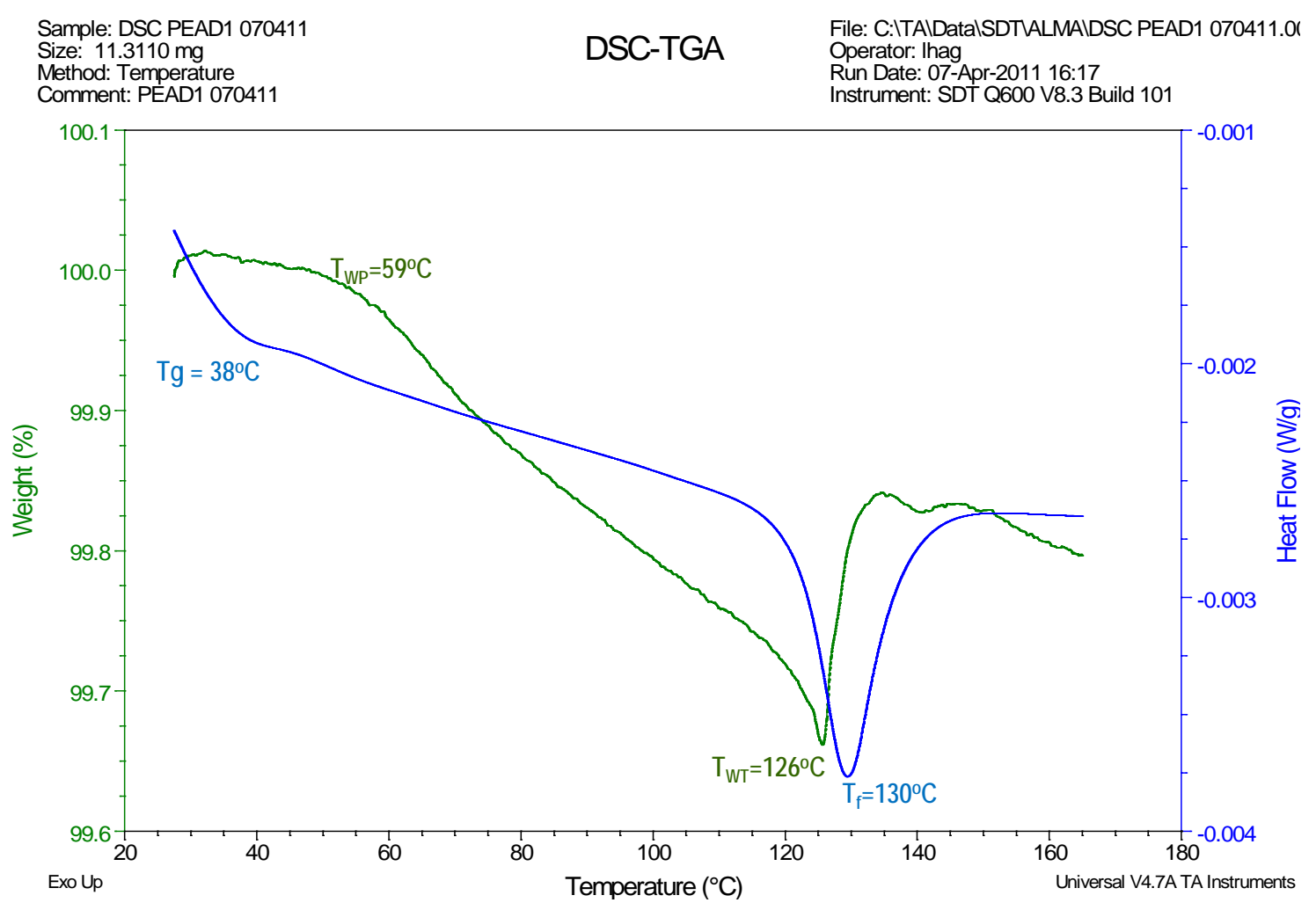

Figure 3. Thermogravimetric analysis of microparticles HDPE (raw material).

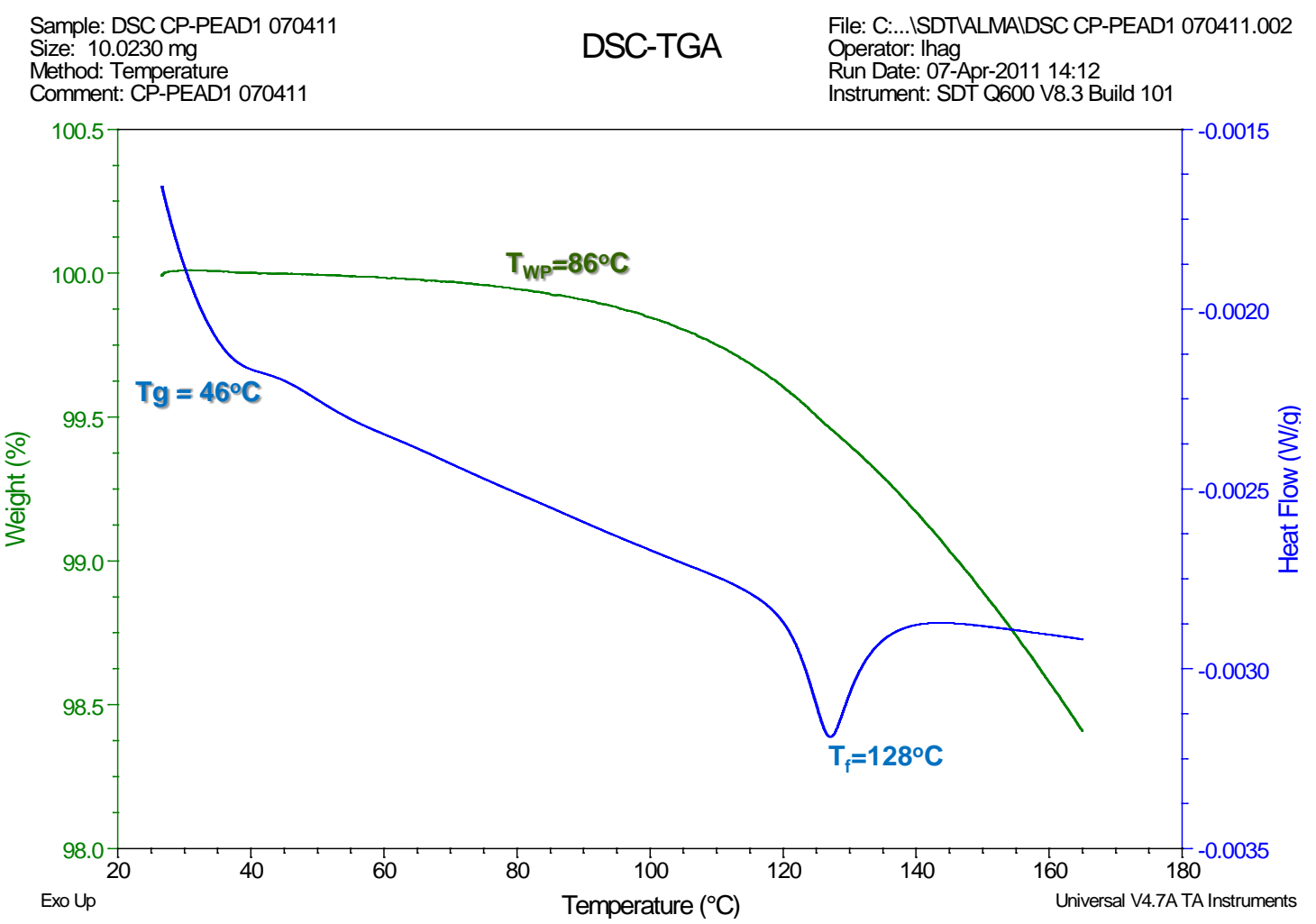

Figure 4. Thermogravimetric analysis of polymeric concrete with microparticles HDPE, mechanically recycled as reinforcing material. 
is considered as a thermoplastic. HDPEPC developed can be softened, processed and reprocessed by the temperature and pressure modification, allowing the desired shape.

The thermal analysis methods are of great importance for the characterization of the thermoplastic materials, due to the large ratio between their properties and temperature. The thermogravimetric analysis measures the weight change of sample under isothermal conditions, or under programmed heating, usually in a linear behavior.

In the SDT-600 equipment the deflection of the balance scale is automatically compensated by an electrical modulator unit by suitable sensors typically thermocouples; it is achieved that the electrical signal is directly proportional to the variation in weight of the sample.

This method is used primarily to investigate mixtures of organic substances as in many cases. The range of the decomposition temperature makes possible the identification and characterization of the specimen by recording the glass transition temperature and weight loss.

\section{References}

[1] Smith, W.F. (2003) Fundamentals of Materials Science and Engineering. 3rd Edition, McGraw Hill.

[2] Mangonon, P.L. (2001) Science of Materials. Institute of Technology. Prentice Hall Pearson Education, Florida.

[3] Blanco, O.R. (2000) Plastic Encyclopedia 2000. Mexican Institute of Industrial Plastic. S.C., 3rd Edition.

[4] Vincent Vela, M.C., et al. (2003) Ingeniería Química y Nuclear. Ciencia y tecnología de polímeros. Capítulo VII Estructura y Propiedades de los Polímeros. Editorial Universidad Politécnica de Valencia, España. 
Scientific Research Publishing (SCIRP) is one of the largest Open Access journal publishers. It is currently publishing more than 200 open access, online, peer-reviewed journals covering a wide range of academic disciplines. SCIRP serves the worldwide academic communities and contributes to the progress and application of science with its publication.

Other selected journals from SCIRP are listed as below. Submit your manuscript to us via either submit@scirp.org or Online Submission Portal.
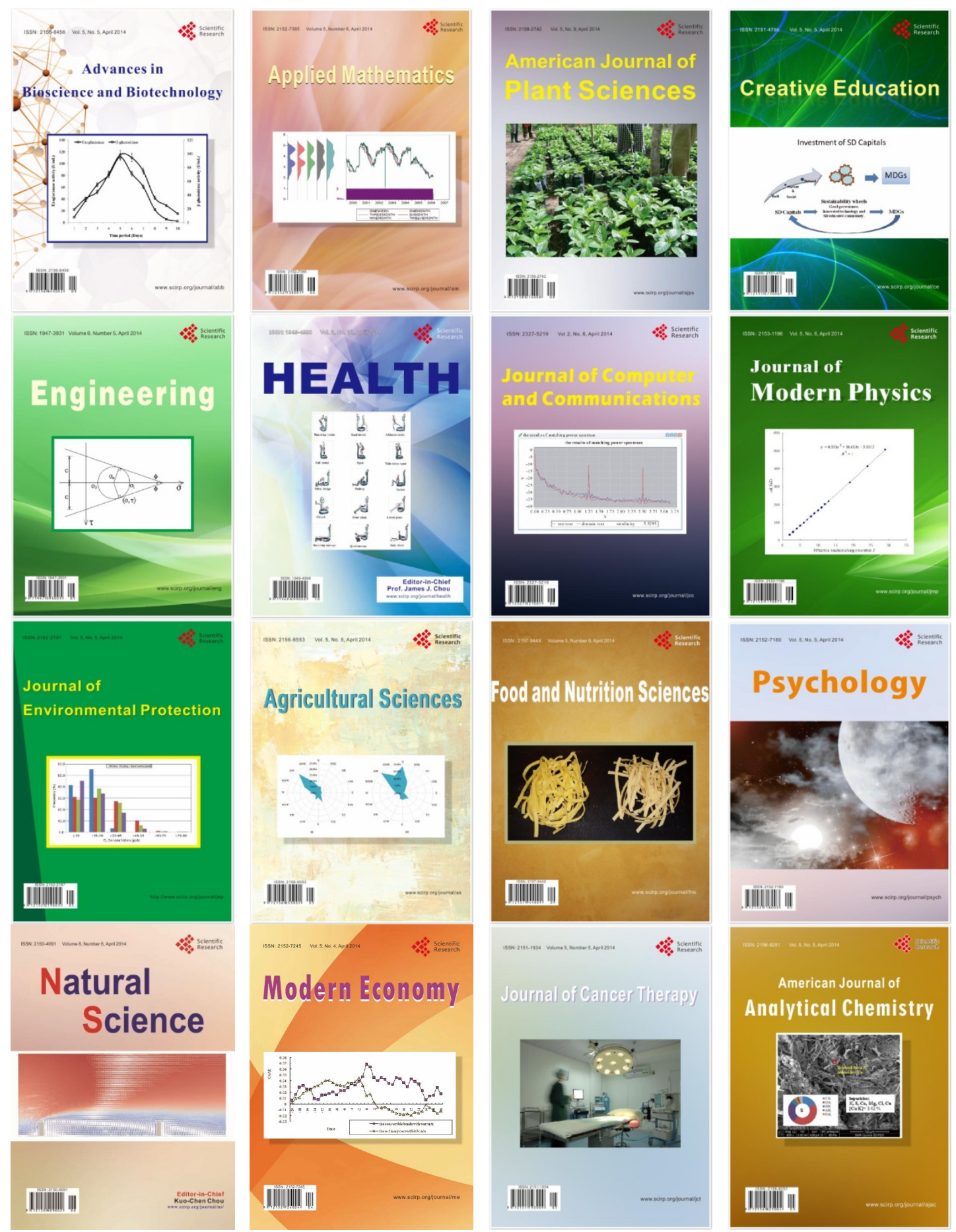